\title{
Malaria prevention knowledge, attitudes, and practices in Zambezia Province, Mozambique
}

\author{
Liliana de Sousa Pinto ${ }^{*}$ (D) Jorge A. H. Arroz ${ }^{1}$, Maria do Rosário O. Martins², Zulmira Hartz², Nuria Negrao ${ }^{3}$,
} Victor Muchanga ${ }^{4}$, Amadeu Cossa ${ }^{4}$ and Rose Zulliger ${ }^{5}$

\begin{abstract}
Background: In Mozambique, socio-economic and cultural factors influence the wide adoption of disease preventive measures that are relevant for malaria control strategies to promote early recognition of disease, prompt seeking of medical care, sleeping under insecticide-treated nets (ITNs), and taking intermittent preventive treatment for pregnant women. However, there is a critical information gap regarding previous and ongoing malaria social and behavioural change (SBC) interventions. The aim of this study is to assess the knowledge, attitudes, practices of beneficiaries of SBC interventions.
\end{abstract}

Methods: A descriptive cross-sectional survey was undertaken in 2018 in two rural districts of Zambezia Province, Mozambique. A structured questionnaire was administered to 773 randomly selected households. Respondents were the adult heads of the households. Descriptive statistics were done.

Results: The main results show that $96.4 \%$ of respondents recalled hearing about malaria in the previous 6 months, $90.0 \%$ had knowledge of malaria prevention, and $70.0 \%$ of preventive measures. Of the $97.7 \%$ respondents that had received ITNs through a mass ITN distribution campaign, $81.7 \%$ had slept under an ITN the night before the survey. In terms of source of health information, $70.5 \%$ mentioned the role of community volunteers in dissemination of malaria prevention messages, $76.1 \%$ of respondents considered worship places (churches and mosques) to be the main places where they heard key malaria prevention messages, and $79.1 \%$ asserted that community dialogue sessions helped them better understand how to prevent malaria.

Conclusions: Results show that volunteers/activists/teachers played an important role in dissemination of key malaria prevention messages, which brought the following successes: community actors are recognized and people have knowledge of malaria transmission, signs and symptoms, preventive measures, and where to get treatment. There is, however, room for improvement on SBC messaging regarding some malaria symptoms (anaemia and convulsions) and operational research is needed to ascertain the drivers of malaria prevalence and inform the SBC approach.

Keywords: Knowledge, Attitude, Practices, Mozambique, Malaria, Social and behaviour change

*Correspondence: liapinto83@gmail.com

${ }^{1}$ Mozambique Medical Coucil, Maputo, Mozambique

Full list of author information is available at the end of the article

\section{Background}

In 2018, there were an estimated 228 million cases of malaria globally, the vast majority $(93 \%)$ in the African region [1]; Mozambique is one of the six countries to account for more than half of all malaria cases. It is 
important to understand the factors that contribute to such a high disease burden in the country.

The World Health Organization's Global Technical Strategy for Malaria 2016-2030 is comprised of three major pillars with two supporting elements: (i) innovation and research, and, (ii) a strong enabling environment [2]. These supporting elements are aligned with the Mozambican National Malaria Control Programme (NMCP) for the elimination of malaria through implementation of research to optimize the impact and costeffectiveness of new and existing tools, interventions and strategies, strong political and financial commitments, multi-sectorial approaches, stewardship of the health system, and capacity building development [3].

The NMCP prioritizes planning, implementation, monitoring, and evaluation based on an evidence-based, multi-cultural, and gender equality approach and an interpersonal communication and mass media (radio) approach [3]. However, there is a critical information gap about outcomes and impact of social and behavioural change (SBC) interventions in Mozambique [3]. SBC interventions are widely used in malaria prevention and control programmes to promote appropriate care-seeking and provision and utilization of insecticide-treated nets (ITNs) and indoor residual spraying (IRS). These interventions play an important role in increasing knowledge and creating awareness and the demand for prevention and treatment programmes [4]. Human behaviour is an important factor contributing to disease burden [5]. It is important to do formative research into various aspects that influence human behaviour, such as individual preferences, community characteristics, leadership practices, and quality of available goods and services, to determine their impact and to design effective SBC strategies and interventions [5]. Behavioural research is also useful for evaluation of SBC interventions.

In Mozambique, the goal of research on SBC interventions is to identify knowledge, attitudes, practices (KAP), and behaviours of communities, in order to define key strategies, target groups, cultural barriers, and community beliefs for improving malaria health outcomes through the adoption of positive health behaviours $[3,6]$. This finding is similar to a study conducted in rural Tanzania which demonstrated that more research on malaria knowledge and beliefs of the community is necessary to obtain and maintain community engagement and participation in malaria control activities [7]. The importance of obtaining this knowledge was underlined in a study conducted in Southeastern Iran that showed that strategies for the control of malaria can be effective, useful and valuable if prior studies are taken to explore and understand people's KAP [8]. In addition, and encouragingly, a study from rural Uganda indicated that communities with knowledge can influence practices in households and support control of the disease [9]. In areas with high burden of disease it is important to have a clear understanding of the community to design good SBC interventions.

The present study was conducted with the aim of assessing the KAP of beneficiaries of malaria prevention SBC interventions in rural Mozambique.

\section{Methods}

\section{Study area and design}

This study was a cross-sectional survey carried out in November and December 2018 in Namacurra and Nicoadala districts of Zambézia Province. The districts were selected based on: (i) high malaria incidence; (ii) accessibility; (iii) population size similarities; (iv) geographic location; and, (v) experience with SBC interventions. The estimated population of Namacurra and Nicoadala is 390,410 and 270,825 inhabitants, respectively [10]. Both are rural districts with more than $60 \%$ of the population being illiterate and living in low social and economic conditions. The main public health problems are: malaria, HIV and diarrhoeal diseases [11]. In 2017, the incidence of malaria (per 1000 inhabitants) in Namacurra was 272 and in Nicoadala was 506 [12]. Both districts have targeted SBC and vector control interventions. SBC interventions included training of volunteers, local religious and community leaders, members of community structures, schoolteachers, and community health workers. These are all community actors that play an important role in dissemination of malaria prevention key messages. Additionally, different communication channels used to reach community members by these actors include meetings with health committee councils and health facilities, dissemination of standardized malaria SBC messages through community radios, door to door visits, sermons at worship places (mosque and church), community dialogues, focus groups discussions with adults, and dissemination of information, education and communication materials. Health committee councils, focal groups discussions (men to men, women), and community dialogues are part of the Mozambique National Health Promotion Strategy to promote and protect individual, family and community health by promoting positive health behaviours. Previously validated community dialogues are also used [13]. Community dialogues to promote healthy living habits are based on a set of 'Life Stories' prepared and used in a series of sessions to stimulate dialogue between people living in the same geographic area (neighbourhoods or communities). Additionally, women and men are given tools that enable them to reflect on how gender norms and social roles work in their lives, and the skills to begin a process of changing those norms, beliefs and roles that are 
considered harmful to health and the environment, and to the social well-being of people and communities, while reinforcing those that are perceived as positive and to be maintained [13].

Many of these efforts, particularly promotion on net use, were connected to the ITN universal coverage campaign (UCC) distribution, which covered the population of each district in 2017, and through ITN distribution in antenatal care (ANC) services to pregnant women. UCC in 2017 distributed 161,591 ITNs in Namacurra (100\% of target) and 125,161 ITNs in Nicoadala (86\% of target) [14].

All localities of these districts were selected for the study. Within each locality, household sample size was calculated by dividing the total sample size of the district by the number of existing localities. Households, the sampling units used in this study, were selected using a systematic random sampling method, after determining the total number in each locality.

\section{Sample size}

Sample size was calculated based on the equation:

$$
n=Z^{2} \times p \times(1-p) / d
$$

where: $\mathrm{n}=$ sample size; $\mathrm{Z}=1.96$ (assuming a level of confidence of 95\%); $\mathrm{p}=$ proportion $=0.5 ; \mathrm{d}=$ error $=0.05$. A total of 768 households were required for the study, 384 per district. The households were divided between localities with sample size equal to the proportion of households per locality. Additionally, five households were added during data collection, resulting in a study population of 773 households.

\section{Selection of households}

In each locality, the households were selected based on the following strategy: first, a household list (sampling frame) was developed and a number was assigned to each household; then, the sample interval (number of households divided by sample size) was computed and a random start number was chosen; finally, from this first random number, households were systematically selected using the sampling interval until the calculated sample size was met.

\section{Data collection and measurement}

A structured, close-ended questionnaire was pre-tested and administered by previously trained local interviewers. The first section of the questionnaire included standardized socio-demographic questions based on the Malaria Indicator Survey 2018 and the following parts of the questionnaire assessed the head of the household malaria KAP/behaviours, and information channels. The questionnaire was designed in Portuguese, and the interviews were conducted in the local language, Enlowe. The questionnaire was pre-tested in a district similar to the study districts. The head of the household was defined as the primary decision-maker in the family and the household and as an individual living in the household and having meals from a common cooking facility [15]. A responsible adult, 18-years or older, was appointed to participate in the interview in the absence of the head of the household.

\section{Variables}

The variables selected for this study were: place of residence, age, gender, level of education, number of people that live in the household, information channels, malaria KAP.

\section{Household inclusion criteria}

The inclusion criteria used to select the households for the study were: (i) households from the selected districts; (ii) household members living in the district from 2011 to 2017 (this period covers the SBC interventions funded by different malaria donors); (iii) interviewee at least 18 years old (head of the household), regardless of gender; (iv) community located in the study districts in which SBC interventions were performed by local community actors (volunteers from community structures, schoolteacher facilitators, activists, and faith leaders); (v) mosquito net mass distribution campaigns; and, (vi) presence of community radios.

\section{Outcomes of interest}

The measured outcomes were: (i) percentage of people who remember hearing or seeing a message about malaria in the previous 6 months; (ii) percentage of people with favourable attitudes towards ITNs, malariarelated practices (use of ITNs, taking anti-malarials) and services (timely demand for health, institutional or community services when noticing signs and symptoms of malaria); (iii) percentage of people who believe the majority of their friends and communities practice the behaviours (using ITNs and seeking counselling and health care services); (iv) percentage of people who identify the mosquito as a cause/vector of malaria; (v) percentage of people who recognize the main signs and symptoms of malaria; (vi) percentage of people who know about treatment for malaria; (vii) percentage of people who know malaria prevention measures; (viii) percentage of households with at least one ITN; (ix) percentage of households with one ITN for every 2 people; (x) percentage of people with access to mosquito nets; xi) percentage of people who slept under an ITN the night 
before the survey; and, xii) use/access ratio of mosquito nets: behaviour indicator.

\section{Data and statistical analysis}

After conducting the study, the previously coded questionnaires were reviewed to verify the responses and their validation; later, the data were entered in SPSS for Windows, version 23.0 (IBM; Armonk, NY, USA). Data analysis was based on descriptive and inferential statistical analysis,

\section{Results}

\section{Sociodemographic characteristics of participants}

A total of 773 household heads were interviewed of whom $59 \%$ were females and $41 \%$ males (Table 1 ). The mean age was 34.6 years (range 18-90 years; standard deviation: 7.7). About $27.4 \%$ were illiterate, $63 \%$ had

Table 1 Sociodemographic characteristics of respondents in the selected households from Nicoadala and Namacurra

\begin{tabular}{|c|c|c|}
\hline Characteristics & $N=773$ & Percentage (\%) \\
\hline \multicolumn{3}{|l|}{ Household size } \\
\hline 1 to 3 & 206 & 26.6 \\
\hline 4 to 6 & 385 & 49.8 \\
\hline$\geq 7$ & 182 & 23.5 \\
\hline Total & 773 & 100.0 \\
\hline \multicolumn{3}{|c|}{ Household members frequently present in the last 6 months } \\
\hline 1 to 3 & 203 & 26.3 \\
\hline 4 to 6 & 386 & 49.9 \\
\hline$\geq 7$ & 184 & 23.8 \\
\hline Total & 773 & 100.0 \\
\hline \multicolumn{3}{|l|}{ Gender } \\
\hline Male & 317 & 41.0 \\
\hline Female & 456 & 59.0 \\
\hline Total & 773 & 100.0 \\
\hline \multicolumn{3}{|l|}{ Age (years) } \\
\hline$<18$ & 26 & 3.4 \\
\hline 18 to 24 & 209 & 27.0 \\
\hline 25 to 34 & 175 & 22.6 \\
\hline 35 to 49 & 206 & 26.6 \\
\hline 50 to 64 & 114 & 14.7 \\
\hline $65+$ & 27 & 3.5 \\
\hline Unknown & 16 & 2.1 \\
\hline Total & 773 & 100.0 \\
\hline \multicolumn{3}{|c|}{ Level of education completed } \\
\hline No education & 212 & 27.4 \\
\hline Primary and elementary & 487 & 63.0 \\
\hline Basic & 65 & 8.4 \\
\hline Secondary & 8 & 1.0 \\
\hline Tertiary and university & 1 & 0.1 \\
\hline Total & 773 & 100.0 \\
\hline
\end{tabular}

completed primary school, and $8.4 \%$ had basic education. About half of the respondents (49.9\%) lived in households with 4 to 6 people, a quarter (26.3\%) in households composed of 1 to 3 members, and the remainder in households with 7 members or more (23.8\%). Detailed socio-demographic characteristics are presented in Table 1.

\section{Knowledge regarding malaria prevention and treatment}

Table 2 shows that within 773 household heads, about 96\% reported having heard and 3.3\% never having heard about malaria. However, the majority of respondents (96.4\%), recalled hearing about malaria in the previous 6 months.

Most respondents (83.4\%) reported that malaria is transmitted through mosquito bites. Regarding recognition of malaria symptoms, headache was pointed to as one of the main symptoms of malaria by both male (48.9\%) and female (48.7\%) respondents. Body pain was the second most mentioned symptom by $39.1 \%$ of males and $34.2 \%$ of females. About $3.9 \%$ of respondents were unable to identify any symptoms of malaria. In Table 3 , it can be noted that the most frequently reported malaria preventive measure was the use of ITNs (72.2\%). More men $(76 \%)$ reported the use of an ITN than women (70\%), burning garbage and creating smoke to chase away mosquitoes (35\%) and improving the cleanliness and hygiene of house and yard (24\%) were other preventive measures mentioned by more than a fifth of respondents. IRS was one of the least mentioned forms of prevention (4.3\%). The use of insecticide products and repellents were rarely mentioned, $3.1 \%$ and $1.8 \%$, respectively.

\section{Practices of malaria prevention, ownership and use of bed nets in target communities}

About $80 \%$ of respondents reported having at least one bed net hanging at home, $21 \%$ reported having only one, $37.2 \%$ having two, $26.7 \%$ having three, and $13.3 \%$ having

Table 2 Reported exposure to information about malaria

\begin{tabular}{lll}
\hline Variable & $\mathbf{N}$ & Percentage (\%) \\
\hline Ever heard of malaria? & 695 & 96 \\
Yes & 26 & 3.3 \\
No & 52 & 6.7 \\
Without answer & 773 & $100.0 \%$ \\
Total & \\
If yes, any exposure in the previous 6 months? & \\
Yes & 695 & 100 \\
No & 0 & 0 \\
Total & 695 & 100.0 \\
\hline
\end{tabular}


Table 3 Level of knowledge about malaria

\begin{tabular}{|c|c|c|c|c|c|c|c|c|}
\hline \multirow[t]{2}{*}{ Type of Knowledge } & \multicolumn{2}{|l|}{ Male } & \multicolumn{2}{|l|}{ Female } & \multirow[t]{2}{*}{ OR } & \multirow[t]{2}{*}{$95 \% \mathrm{Cl}$} & \multicolumn{2}{|l|}{ Total } \\
\hline & $\mathrm{N}=317$ & (\%) & $\mathrm{N}=456$ & (\%) & & & $\mathrm{N}=773$ & (\%) \\
\hline \multicolumn{9}{|c|}{ Reported cause of malaria transmission } \\
\hline Mosquito bite & 271 & 85.5 & 374 & 83.4 & 1.68 & $1.20-2.34^{*}$ & 645 & 83.4 \\
\hline Garbage/dirt near the house & 84 & 26.5 & 135 & 29.6 & 1.17 & $0.84-1.61$ & 219 & 28.3 \\
\hline Others (fleas/lice) & 49 & 15.5 & 67 & 14.7 & 0.94 & $0.63-1.41$ & 116 & 15.0 \\
\hline Does not know & 17 & 5.4 & 31 & 6.8 & 1.28 & $0.70-2.36$ & 48 & 6.2 \\
\hline \multicolumn{9}{|l|}{ Recognition of symptoms } \\
\hline Body pain & 124 & 39.1 & 156 & 34.2 & 0.81 & $0.60-1.08$ & 280 & 36.2 \\
\hline Headaches & 155 & 48.9 & 222 & 48.7 & 0.99 & $0.74-1.32$ & 377 & 48.8 \\
\hline Joint pain & 74 & 23.3 & 133 & 29.2 & 1.36 & $0.97-1.88^{*}$ & 207 & 26.8 \\
\hline Diarrhoea & 39 & 12.3 & 86 & 18.9 & 1.66 & $1.10-2.49^{*}$ & 125 & 16.2 \\
\hline Vomit & 46 & 14.5 & 114 & 25.0 & 1.96 & $1.34-2.86^{*}$ & 160 & 20.7 \\
\hline Lack of appetite & 49 & 15.5 & 80 & 17.5 & 1.16 & $0.79-1.71^{*}$ & 129 & 16.7 \\
\hline Cough & 5 & 1.6 & 7 & 1.5 & 0.97 & $0.30-3.09$ & 12 & 1.6 \\
\hline Nasal congestion & 1 & 0.3 & 1 & 0.2 & 0.69 & $0.04-11.1$ & 2 & 0.3 \\
\hline Does not know & 9 & 2.8 & 21 & 4.6 & 1.65 & $0.74-3.65$ & 30 & 3.9 \\
\hline \multicolumn{9}{|c|}{ Reported malaria preventive measures } \\
\hline Burn leaves/eucalyptus & 14 & 4.4 & 40 & 8.8 & 2.08 & $1.12-3.89^{*}$ & 54 & 7.0 \\
\hline Insecticide serpentine/spray & 4 & 1.3 & 20 & 4.4 & 3.63 & $1.23-10.7^{*}$ & 24 & 3.1 \\
\hline Mosquito net & 241 & 76.0 & 319 & 70.0 & 0.73 & $0.53-1.01^{*}$ & 558 & 72.2 \\
\hline Repellent & 3 & 0.9 & 11 & 2.4 & 2.59 & $0.71-9.35$ & 14 & 1.8 \\
\hline Burn garbage & 112 & 35.3 & 156 & 34.2 & 0.95 & $0.70-1.28$ & 268 & 34.7 \\
\hline Traditional treatment & 3 & 0.9 & 6 & $1.3 \%$ & 1.39 & $0.34-5.62$ & 9 & 1.2 \\
\hline Improve home hygiene & 79 & 24.9 & 109 & 23.9 & 0.95 & $0.67-1.32$ & 188 & 24.3 \\
\hline Spraying/fumigate the house & 8 & $2.5 \%$ & 25 & 5.5 & 2.24 & $0,99-5.30^{*}$ & 33 & 4.3 \\
\hline Improve individual hygiene & 16 & $5.0 \%$ & 15 & 3.3 & 0.65 & $0.31-1.31$ & 31 & 4.0 \\
\hline None/does not know & 23 & $7.3 \%$ & 42 & 9.2 & 1.29 & $0.76-2.20$ & 65 & 8.4 \\
\hline
\end{tabular}

$O R$ odds ratio, $\mathrm{Cl}$ confidence interval

* Significant association $(p<0.05)$

four or more. Most of the respondents (97.7\%) reported that they received bed nets through the mass universal coverage ITN distribution campaign, and $82.7 \%$ reported sleeping under the bed net the night before the survey (Tables 4 and 5).

\section{Beneficiaries' attitudes towards malaria prevention, diagnosis and treatment}

From the 721 respondents that reported exposure to information about malaria, $86.3 \%$ felt confident about their knowledge of how to prevent malaria and $96.4 \%$ knew where to get treatment. Regarding the use of bed nets at night, $96.9 \%$ of respondents considered it an important prevention from malaria. Most of the respondents (69.2\%) reported that family members, friends and neighbours influence their decision-making regarding their health and $23.6 \%$ disagreed with this assertion (Table 6).
Table 7 shows attitudes regarding measures adopted for malaria diagnosis and febrile symptoms. From the 721 heads of household that had heard of malaria, 539 (74.8\%) reported a household member with a fever in the previous 6 months. In 409 households a family member was reported to have had a fever in the two weeks prior to the survey, among whom 395 reported seeking counselling and treatment from health facilities, 10 from the market, and 4 from other places. Participants reported that they sought care at the health facility services because it had better quality/was more efficient (66.1\%), and was less expensive $(22.0 \%)$. The person who decided where to seek counselling and treatment was generally the head of the household (72.9\%), followed by the spouse of head of household (16\%), then the person with fever (9.0\%). From 395 households, 359 reported a rapid diagnostic test (RDT) was taken by a health worker and the remaining 39 were not tested. Of 359 respondents who were tested, 
Table 4 Treated bed net ownership

\begin{tabular}{lcc}
\hline Variables & N & Percentage (\%) \\
\hline Households has at least one bed net hanging at home & \\
Yes & 618 & 79.9 \\
No & 103 & 13.3 \\
No answer & 52 & 6.7 \\
Total & 773 & 100.0 \\
Number of bed nets at home & & \\
One bed net & 131 & 21.2 \\
Two bed net & 230 & 37.2 \\
Three bed net & 165 & 26.7 \\
Four bed net & 53 & 8.6 \\
Five or more & 29 & 4.7 \\
Don't know & 10 & 1.6 \\
Total & 618 & 100.0 \\
Source of bed net & & \\
Universal coverage campaign & 604 & 97.7 \\
Antenatal care & 4 & 0.6 \\
Don't know & 10 & 1.6 \\
Other places & 0 & 0.0 \\
Total & 618 & 100.0 \\
\hline
\end{tabular}

$89.7 \%$ obtained a positive result, $0.8 \%$ negative, and $9.5 \%$ did not know their result.

\section{Attitudes of beneficiaries regarding malaria prevention}

As shown in Table 8 , around $70.5 \%$ of respondents felt that community volunteers were ready to disseminate key malaria prevention messages. From 721 respondents, $76.1 \%$ identified worship places (churches and mosques) where they heard key messages on malaria prevention. Some $79.1 \%$ strongly agreed that community dialogue sessions helped them better understand how to prevent malaria. For the respondents, volunteers/activists/teachers played an important role in the dissemination of key malaria prevention messages.

\section{Discussion}

Most malaria prevention strategies are centred on human behaviour and SBC interventions are a key part of the NMCP malaria strategy. This study assessed malaria prevention and treatment KAP in two rural Mozambican districts, Namacurra and Nicoadala.

The results show that almost all respondents had heard about malaria in the previous 6 months and those in these rural Zambezia districts have at least some knowledge of malaria causes, symptoms, treatment, and preventive measures. These results are similar to those obtained in other studies [7-9, 15], implying that the SBC campaigns of previous years have been successful at reaching people in rural Mozambique and somewhat successful at disseminating education messages. However, it is important to note that although most respondents knew that malaria is transmitted by the mosquito bite, they did not associate it with other people (i.e., with "bites of mosquito which bit a malarial patient"). This lack of knowledge has been reported before [8, 15], and is an indication that messaging on this aspect of transmission needs to be improved. Headaches were identified as the main symptom of malaria, similar to a study conducted by Khumbulani et al. [16]. However, despite relatively good knowledge of malaria symptoms and signs, respondents failed to name anaemia and convulsions. This lack of information could lead to a delay in seeking appropriate care from health facilities or community health workers. It is important to improve the training of local health community actors and subsequently improve dissemination and explanation to beneficiaries.

Most respondents felt confident and knew about malaria prevention methods and where to seek treatment, and considered the use of bed nets important to prevent and protect from malaria, which is similar to a study conducted in Ethiopia where the majority of respondents considered the mosquito net a protective measure against mosquito bites [17]. ITNs are a key part of malaria prevention strategies. ITNs are distributed through key channels, with most distributed through mass distribution campaigns and through antenatal care consultations [1]. In Mozambique $68 \%$ of the population sleeps under a bed net (40\% under LLINs). These results show that previous SBC campaigns on bed nets have likely been successful in rural Zambezia as this were among the most recognized prevention form among the respondents, most of them having at least one bed net hanging at home which they use every night.

Table 5 Bed net usage

\begin{tabular}{|c|c|c|c|c|c|c|c|c|}
\hline \multirow{2}{*}{$\begin{array}{l}\text { Did you sleep under a } \\
\text { bed net the night before }\end{array}$} & \multicolumn{2}{|l|}{ Male } & \multicolumn{2}{|l|}{ Female } & \multirow[b]{2}{*}{ OR } & \multirow[b]{2}{*}{$95 \% \mathrm{Cl}$} & \multicolumn{2}{|l|}{ Total } \\
\hline & Freq. $(\mathrm{N}=301)$ & Perc. (\%) & Freq. $(\mathrm{N}=420)$ & Perc (\%) & & & Freq. $(\mathrm{N}=618)$ & Perc. (\%) \\
\hline Yes & 224 & 86.8 & 287 & 79.7 & 0.55 & $0.35-0.85^{*}$ & 511 & 82.7 \\
\hline No & 34 & 13.2 & 73 & 20.3 & & & 107 & 17.3 \\
\hline
\end{tabular}

* $p$ value 0.003 
Table 6 Attitudes of beneficiaries regarding malaria prevention

\begin{tabular}{lrc}
\hline Variables & N & Percentage (\%) \\
\hline I feel confident that I know how to prevent malaria & \\
Disagree or strongly disagree & 70 & 9.7 \\
Neutral & 29 & 4.0 \\
Agree or strongly agree & 622 & 86.3 \\
Total & 721 & 100.0 \\
I know where I can get treatment for malaria & & \\
Disagree or strongly disagree & 16 & 2.2 \\
Neutral & 10 & 1.4 \\
Agree or strongly agree & 695 & 96.4 \\
Total & 721 & 100.0 \\
The use of a bed net every night is important so that I can protect \\
myself from getting malaria & 17 & 2.4 \\
Disagree or strongly disagree & 5 & 0.7 \\
Neutral & 699 & 96.9 \\
Agree or strongly disagree & 721 & 100.0 \\
Total & & \\
My family, friends and neighbours influence my decision-making & & \\
regarding my health & 170 & 23.6 \\
Disagree or strongly disagree & 52 & 7.2 \\
Neutral & 499 & 69.2 \\
Agree or strongly agree & 721 & 100.0 \\
Total & & \\
\hline
\end{tabular}

Additionally, most reported sleeping under a bed net the night before the survey, which is similar to other studies conducted in the country $[7,15,18]$.

Despite the wide availability of bed nets in the region and the indication from the results that the community uses them, the prevalence of malaria in Zambezia Province in children aged 6 to 59 months (using the malaria diagnostic test) increased from $38.3 \%$ in 2011 [19], 40.2\% in 2015 [20] and 39\% in 2018 [15]. Whilst efforts to support improved and regular use of nets by all is required, which may need more nuanced messaging for different audiences, other methods of vector control may also need to be investigated for a further reduction in prevalence.

In this study, health facilities were most commonly used for malaria treatment. This observation is similar to other studies [7, 21], and it was pointed out as being the more effective and less expensive place to go to. The decision about where to go to receive treatment was the responsibility of the head of the household. Data show that family members, friends and neighbours were the greatest influencers on decision-makers regarding health of members of the household, similar to a study conducted in Nigeria, where it was indicated that family members play a role on health decisions [22]. This reinforces the importance of having strategies and approaches in SBC to target greatest influencers.
The majority of respondents consider community volunteers/activists/teachers are very well trained and they play an important role in disseminating key malaria preventive messages. These findings are collaborated by a study conducted in Kenya which showed that community actors are very well accepted during community implementation of SBC interventions [23]. Worship places (churches and mosques) are where respondents heard malaria preventive messages, and community dialogue sessions helped them better understand how to prevent malaria. Similarly, in a study conducted in Nampula Province, Mozambique, respondents affirmed that community dialogues helped communication and ultimately encouraged malaria-related behaviour [24]. These results indicate that the people implementing SBC interventions in Mozambique aid in dissemination of information and are accepted interlocutors by the beneficiaries.

This study has some limitations: it targeted the head of household as a proxy to KAP held by all members of a household. Ideally, a broader sampling method across the range of adults within Nicoadala and Namacurra communities should have been used. However, this was not possible due to funding constraints. The results may not accurately represent the community's perspectives as a whole. Another limitation of the study is that people in these communities could have obtained information from sources other than the formal SBC interventions, e.g., social media or informal conversations. One cannot attribute all of the success to previous formal SBC interventions. All reported behaviours were self-reported and may have been affected by social desirability bias. Additionally, the questionnaire was not designed to document net quality. Low net quality might have influenced the effectiveness of the intervention, as noted in other studies from Mozambique [25].

\section{Conclusions}

This study confirms that SBC interventions carried out in rural Mozambique have had many successes. Namely, most people have knowledge of malaria prevention and treatment. The study shows that beneficiaries have bed nets and widely report the use of them. Beneficiaries recognized the role of community actors (teachers, community health workers, religious leaders) in dissemination of malaria key preventive messages. It was identified that there is room for improvement on SBC messaging regarding malaria symptoms. Specifically, that people recognize anaemia and convulsions as malaria symptoms so that they quickly seek health care services. Moreover, the study raises the need for further research into the main drivers of malaria prevalence in the country and the need to conduct operational research to refine SBC approaches. 
Table 7 Beneficiaries' attitudes towards malaria diagnosis and treatment

\begin{tabular}{|c|c|c|}
\hline Variables & $\mathbf{N}$ & Percentage (\%) \\
\hline \multicolumn{3}{|c|}{ Household member had a fever in the previous 6 months } \\
\hline Yes & 539 & 74.8 \\
\hline No & 175 & 24.3 \\
\hline Does not know/does not remember & 7 & 1.0 \\
\hline Total & 721 & 100.0 \\
\hline \multicolumn{3}{|c|}{ Household member had a fever in the previous two weeks } \\
\hline Yes & 409 & 56.7 \\
\hline No & 273 & 37.9 \\
\hline Does not know/Does not remember & 5 & 0.7 \\
\hline Total & 687 & 95.3 \\
\hline \multicolumn{3}{|c|}{ Did you look for someone for malaria treatment? } \\
\hline Yes & 409 & 100 \\
\hline No & 0 & 0 \\
\hline Total & 409 & 100 \\
\hline \multicolumn{3}{|c|}{ Where did you seek counselling and treatment? } \\
\hline Health Facility & 395 & 96.6 \\
\hline Market & 10 & 2.4 \\
\hline Another place & 4 & 1.0 \\
\hline Total & 409 & 100.0 \\
\hline \multicolumn{3}{|c|}{ Reason sought advice or treatment from this provider } \\
\hline More efficient/competent/better quality & 261 & 66.1 \\
\hline Less expensive & 87 & 22.0 \\
\hline Close to their residency & 36 & 9.0 \\
\hline Other reason & 11 & 3.0 \\
\hline Total & 395 & 100.0 \\
\hline \multicolumn{3}{|c|}{ Who decided where you went to for counselling/treatment? } \\
\hline Head of household & 290 & 72.9 \\
\hline Wife of the head of household & 67 & 16.8 \\
\hline Mother-in-law & 1 & 0.3 \\
\hline The person with the fever & 36 & 9.0 \\
\hline Other & 4 & 1.0 \\
\hline Total & 395 & 100.0 \\
\hline \multicolumn{3}{|l|}{ Reported use of malaria test } \\
\hline Yes & 359 & 90.2 \\
\hline No & 39 & 9.8 \\
\hline Total & 395 & 100.0 \\
\hline \multicolumn{3}{|l|}{ Malaria test result } \\
\hline Positive & 322 & 89.7 \\
\hline Negative & 3 & 0.8 \\
\hline Do not know & 34 & 9.5 \\
\hline Total & 359 & 100.0 \\
\hline
\end{tabular}

\section{Abbreviations}

HH: Household; ITNs: Insecticide-treated nets; SBC: Social and behavioural change; UCC: Universal coverage campaign; ANC: Antenatal care; NMCP: National Malaria Control Programme; ITN: Insecticide-treated net; IRS: Indoor residual spraying; KAP: Knowledge, attitude and practice; RDT: Rapid diagnostic test.

\section{Acknowledgements}

The authors would like to acknowledge the contributions of the anonymous community members who participated in the interviewing process. They would like to especially thank the household heads for participating in this study. The authors also would like to acknowledge the Zambezia health authorities for the administrative authorization for the study. 
Table 8 Attitudes of beneficiaries regarding malaria prevention

\begin{tabular}{lcr}
\hline Variables & N & Perce \\
\hline $\begin{array}{l}\text { I feel that community volunteers are prepared to spread key m } \\
\text { prevention messages }\end{array}$ & & \\
Disagree or strongly disagree & 86 & 11.9 \\
Neutral & 76 & 10.5 \\
Agree or strongly agree & 559 & 77.5 \\
Total & 721 & 100.0
\end{tabular}

Did you receive sufficient information from the activists?

$\begin{array}{llr}\text { Disagree or strongly disagree } & 113 & 15.7 \\ \text { Neutral } & 102 & 14.1 \\ \text { Agree or strongly agree } & 506 & 70.2 \\ \text { Total } & 721 & 100.0\end{array}$

Tota

Most of my neighbours, my community and my family including myself have the ability to recognize the signs and symptoms of malaria

$\begin{array}{llr}\text { Disagree or strongly disagree } & 90 & 12.5 \\ \text { Neutral } & 46 & 6.4 \\ \text { Agree or strongly agree } & 585 & 81.1 \\ \text { Total } & 721 & 100.0\end{array}$

Worship places (churches and mosques) are where I hear malaria prevention messages

$\begin{array}{lrr}\text { Disagree or strongly disagree } & 133 & 18.4 \\ \text { Neutral } & 39 & 5.4 \\ \text { Agree or strongly agree } & 549 & 76.1 \\ \text { Total } & 721 & 100.0\end{array}$

Community dialogue sessions helped me better understand how to prevent malaria

$\begin{array}{lrr}\text { Disagree or strongly disagree } & 65 & 9.0 \\ \text { Neutral } & 86 & 11.9 \\ \text { Agree or strongly agree } & 570 & 79.1 \\ \text { Total } & 721 & 100.0\end{array}$

Volunteers/activists/teachers play a key role in spreading key messages on malaria prevention

Disagree or strongly disagree $\quad 55 \quad 7.6$

Neutral

$65 \quad 9.0$

Agree or strongly agree $\quad 601 \quad 83.4$

$\begin{array}{lll}\text { Total } & 721 & 100.0\end{array}$

\section{Authors' contributions}

LP conceived and designed the study protocol, analysed the data, drafted the manuscript, and made final revisions. JA and MROM supported the protocol design, performed sample calculations, analysed data, and reviewed the manuscript. RZ supported the design of data collection tool (questionnaire) and reviewed the final manuscript. ZH critically reviewed the manuscript. VM and AM analysed the data and reviewed the manuscript. NN contributed to the writing, editing, and revision of the manuscript. All authors read and approved the final manuscript.

\section{Funding}

This study was funded by the Principal Investigator as part of her Ph.D. thesis. The findings and conclusions in this report are those of the authors.

\section{Availability of data and materials}

The datasets used and/or analysed during the current study are available from the corresponding author upon reasonable request.

\section{Declarations}

Ethics approval and consent to participate

The study was administratively authorized by the Provincial Health Directorate of Zambezia and received authorization from the National Committee on Bioethics in Health (Ref 308/CNBS/2018).The participants were informed about the objectives of the study. They signed an informed consent document to ensure the willingness of participation and they were free to withdraw from the study at any time. Identification numbers were used instead of participant names to maintain the confidentiality throughout the study.

\section{Consent for publication}

Not applicable.

\section{Competing interests}

The authors declare that they have no competing interests.

\section{Author details}

${ }^{1}$ Mozambique Medical Coucil, Maputo, Mozambique. ${ }^{2}$ Global Health and Tropical Medicine, GHTM, Instituto de Higiene E Medicina Tropical, IHMT, Universidade Nova de Lisboa, UNL, Rua da Junqueira 100, 1349-008 Lisboa, Portugal. ${ }^{3}$ Cactus Communications, A/603, Satellite Gazebo, Guru Hargovindji Marg, Andheri East, Mumbai 400093, Maharashtra, India. ${ }^{4}$ Plataforma Inter-Religiosa de Comunicação para Saúde-PIRCOM, Maputo, Mozambique. ${ }^{5}$ Independent Consultant, Maputo, Mozambique.

Received: 7 September 2020 Accepted: 17 June 2021

Published online: 30 June 2021

\section{References}

1. WHO. World Malaria Report. Geneva, World Health Organization; 2019. Available from: https://www.who.int/publications-detail/world-malariareport-2019. Accessed 29 January 2020

2. WHO. Global technical strategy for malaria 2016-30. Geneva, World Health Organization, 2015. Available in: https://www.who.int/malaria/ areas/global_technical_strategy/en/. Accessed 20 September 2019.

3. Ministério da Saúde: National Malaria Controlo Programme. Malaria Strategic Plan 2017-2022. Maputo, Mozambique, 2017.

4. Zalisk K, Herrera S, Inyang U, Mohammed AB, Uhomoibhi P, Yé Y. Caregiver exposure to malaria social and behaviour change messages can improve bed net use among children in an endemic country: secondary analysis of the 2015 Nigeria Malaria Indicator Survey. Malar J. 2019;8:121.

5. President Malaria Initiative (PMI). Malaria Initiative Technical Guidance, 2018

6. Roll Back Malaria Partnership to End Malaria. The Strategic Framework for Malaria Social and Behavior Change Communication 2018-2030. Available in: https://endmalaria.org/sites/default/files/RBM\%20SBCC\%20Fra mework\%202018-2030\%20English.pdf. Accessed 29 January 2020.

7. Mazingo HD, Obasy E, Mauka W, Manyiri P, Zinga M, Kweka EJ, et al. Knowledge, attitudes, and practices about malaria and its control in rural northwest Tanzania. Malar Res Treat. 2020;2010:794261.

8. Nejati J, Moosa-Kazemi SH, Saghafipour A, Soofi K. Knowledge, attitude and practice (KAP) on malaria, from high malaria burden rural communities, southeastern Iran. J Parasit Dis. 2018;42:62-7.

9. Musoke D, Karani G, Sempebwa JC, Etajak S, Guwatudde D, Musoke MB. Knowledge and practices on malaria prevention in two rural communities in Wakiso District. Uganda Afr Health Sci. 2015;15:401-12.

10. Ministerio da Administracao Estatal. Perfil do distrito de Nicoadala, 2014. Available from: http://www.maefp.gov.mz/wp-content/uploads/2017/ 04/Nicoadala.pdft. [Accessed in 8 February 2020]

11. Ministério da Saúde. Programa Nacional de Control da Malaria. Direção Provincial de Saúde Zambézia. Relatório anual. Boletim Epidemiológico de Saúde (BES), SISMA. Maputo, Mozambique, 2017.

12. Ahmed SM, Haque R, Haque U, Hossain A. Knowledge on the transmission, prevention and treatment of malaria among two endemic populations of Bangladesh and their health-seeking behaviour. Malar J. 2009:8:173. 
13. Ministerio da Saude: Direccao nacional de Saude Publica. Estrategia Nacional de Promocao de Saude (2015 - 2019). Maputo, Mozambique, 2015.

14. Ministerio da Saúde. Direcção Provincial da Saúde da Zambezia. Relatório anual 2017. Maputo, Mozambique, 2017.

15. Instituto Nacional de Saúde (INS). Inquérito Nacional Sobre Indicadores de Malária 2018. Maputo, Moçambique, 2018.

16. Hlongwana KW, Mabaso ML, Kunene S, Govender D, Maharaj R. Community knowledge, attitudes and practices (KAP) on malaria in Swaziland: a country earmarked for malaria elimination. Malar J. 2009;8:29.

17. Astatkie A. Knowledge and practice of malaria prevention methods among residents of Arba Minch Town and Arba Minch Zuria district, southern Ethiopia. Ethiop J Health Sci. 2010;20:185-93.

18. Arroz JAH, Candrinho B, Mendis C, Varela P, Pinto J, Martins MDRO. Effectiveness of a new long-lasting insecticidal nets delivery model in two rural districts of Mozambique: a before-after study. Malar J. 2018;17:66.

19. República de Moçambique, Ministério da Saúde, Instituto Nacional de Estatística; MEASURE DHS/ICF International. Inquérito demográfico e de saúde 2011. Maputo, Mozambique, 2011. Available from: http://www. dhsprogram.com/pubs/pdf/FR266/FR266.pdf [Accessed 19th September 2017].

20. Ministério da Saúde (MISAU), Instituto Nacional de Estatística (INE), ICF Internacional, Inquérito de Indicadores de Imunização, Malária e HIV/
SIDA em Moçambique 2015. Maputo, Moçambique. Rockville, Maryland, EUA: INS, INE and ICF International.

21. Sumba PO, Wong SL, Kanzaria HK, Johnson KA, John CC. Malaria treatment-seeking behaviour and recovery from malaria in a highland area of Kenya. Malar J. 2008;7:245.

22. Campbell TH, McDaniel SH, Cole-Kelly K. Family issues in Health care. In: Taylor RB, Ed. Family Medicine Principles and Practices. 6th Edn. New York: Springer-Verlag; 2002

23. Owek CJ, Oluoch E, Wachira J, Estambale B, Afrane YA. Community perceptions and attitudes on malaria case management and the role of community health workers. Malar J. 2017;16:272.

24. Hildon ZJ, Escorcio-Ymayo M, Zulliger R, de Aramburu RA, Lewicky N, Harig $\mathrm{H}$, et al. "We have this, with my husband, we live in harmony": exploring the gendered decision-making matrix for malaria prevention and treatment in Nampula Province. Mozambique Malar J. 2020;19:133.

25. Abílio AP, Obi E, Kilian A, Koenker H, Babalola S, Saifodine A, et al. Monitoring the durability of the long-lasting insecticidal nets MAGNet and Royal Sentry in three ecological zones of Mozambique. Malar J. 2020;19:209.

\section{Publisher's Note}

Springer Nature remains neutral with regard to jurisdictional claims in published maps and institutional affiliations.
Ready to submit your research? Choose BMC and benefit from:

- fast, convenient online submission

- thorough peer review by experienced researchers in your field

- rapid publication on acceptance

- support for research data, including large and complex data types

- gold Open Access which fosters wider collaboration and increased citations

- maximum visibility for your research: over $100 \mathrm{M}$ website views per year

At BMC, research is always in progress.

Learn more biomedcentral.com/submissions 